\title{
Solasodine, Solamargine and Mixtures of Solasodine Rhamnosides: Pathway to Expansive Clinical Anticancer Therapies
}

\author{
Bill E. Cham \\ Australasian Medical Research, Port Vila, Republic of Vanuatu \\ Email:bill.cham@gmail.com
}

How to cite this paper: Cham, B.E. (2017) Solasodine, Solamargine and Mixtures of Solasodine Rhamnosides: Pathway to Expansive Clinical Anticancer Therapies. International Journal of Clinical Medicine, 8, 692-713.

https://doi.org/10.4236/ijcm.2017.812064

Received: December 24, 2017

Accepted: December 26, 2017

Published: December 29, 2017

Copyright $\odot 2017$ by author and Scientific Research Publishing Inc. This work is licensed under the Creative Commons Attribution International License (CC BY 4.0).

http://creativecommons.org/licenses/by/4.0/

\begin{abstract}
Cancer remains a major cause of mortality worldwide. Progresses have been made in the understanding of the molecular basis of cancer, cancer detection, and cancer treatment. Important strides by treating early-stage cancers have resulted in improved outcomes. Despite these achievements, mortality of cancer patients is high and still there is no cure. Some oncologists remain optimistic that cytotoxic chemotherapy will significantly improve cancer survival. However, notwithstanding the use of new and expensive single and more recently, combination drugs, the improvement of the response rates remains very low. In the United States, cancer death rates decreased by a mere $1.4 \%$ to $1.8 \%$ from 2004 to 2013 . Compared to other serious diseases, the improvement of the cancer patient has been disappointingly lagging, and by far, most patients with advanced cancer eventually die of their disease. The need for improved cancer therapies is self-evident. This communication gives an overview of the overwhelming resurgence of solasodine and its glycosides in cancer therapy.
\end{abstract}

\section{Keywords}

Cancer, BEC, Solamargine, Apoptosis, MDR, Metastasis, Curaderm

\section{Introduction}

\subsection{Cytotoxic Chemotherapy}

Cytotoxic chemotherapy refers to agents whose mechanisms of action cause cell death or prevents cell growth and, to date remains one of the premier treatment options to combat cancer. However, the efficacy of chemotherapy is limited by the fact that not all tumors respond optimally. Single and combination modali- 
ties chemotherapy with existing drugs are rarely curative. Drug-resistant tumor cells often emerge when using such therapies. Most standard chemotherapies act on all rapidly dividing normal and cancer cells and were originally identified because they kill cells in general by a process known as indiscriminate cytotoxicity. Consequently, standard chemotherapies are indiscriminate and have low safety profiles.

\subsection{Apoptosis}

Apoptosis is a form of cell death in which a programmed sequence of events leads to the elimination of cells without releasing harmful substances into the surrounding area. Apoptosis eliminates old cells, unnecessary cells, and unhealthy cells. Roughly 50 billion cells undergo apoptosis each day in humans. For every normal cell, there is a time to live and a time to die. When apoptosis does not work correctly, cells that should be eliminated may persist and become immortal, for example in cancer. Cancer can start at any place in the body. It starts when cells grow out of control and crowd out normal cells. In cancer cells, the process of apoptosis is defunct but cell division is intact resulting in excessive numbers of cancer cells, which are prone to spreading to other parts of the body (metastasis). Many cancers develop resistance to chemotherapy drugs and are a major factor in the failure of many forms of chemotherapy. Substances either singly or by combination that can induce cell death in cancer cells, prevent metastasis and do not become resistant to cancer cells are being pursued to treat cancer. Unfortunately, to date, these substances have been elusive. This overview describes solasodine glycosides, used singly or in combination with other drugs, may be the discovery of a truly effective chemotherapy for cancer.

\subsection{The Discovery and Consequences Thereof}

In 1987 we were the first to report that the plant-derived glycoalkaloids solasodine glycosides (SGs), including solamargine (SM), solasonine (SS), mono- and diglycosides of solasodine, known as BEC [1], induced anticancer effects in cell culture [2], animals [3] and humans [4].

More specifically, it was shown that these SGs and in particular SM, induced apoptosis in cancer cells but not normal cells [2] [5]. BEC consists of $33 \%$ of solasonine, $\quad(22 \mathrm{R}, 25 \mathrm{R})$-spiro-5-ene-3 $\beta$-yl- $\alpha$-L-rhamnopyranosyl-(l->2gal)-O- $\beta$-Dglucopyranosyl-(l->3gal)- $\beta$-D-galactopyranose], 33\% solamargine (22R, 25R)spiro-5-ene-3 $\beta$-yl- $\alpha$-L-rhamnopyranosyl-(l->2glu)-O- $\alpha$-L-rhamnopyranosyl- (1- > 4 glu $)-\beta$-D-glucopyranose and $34 \%$ mono- and diglycosides of solasodine.

Figure 1 illustrates the structures of the BEC components.

The sugar moiety of the triglycoside solasonine is:

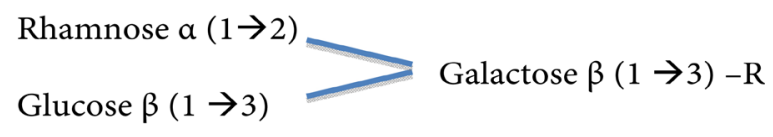

One of the precursor diglycoside molecules is: 
Rhamnose $\alpha(1 \rightarrow 2)=$ Galactose $\beta(1 \rightarrow 3)-\mathrm{R}$

Another diglycoside precursor is:

Glucose $\beta(1 \rightarrow 3)=$ Galactose $\beta(1 \rightarrow 3)-\mathrm{R}$

Its monoglycoside precursor is:

Galactose $\beta(1 \rightarrow 3)-\mathrm{R}$

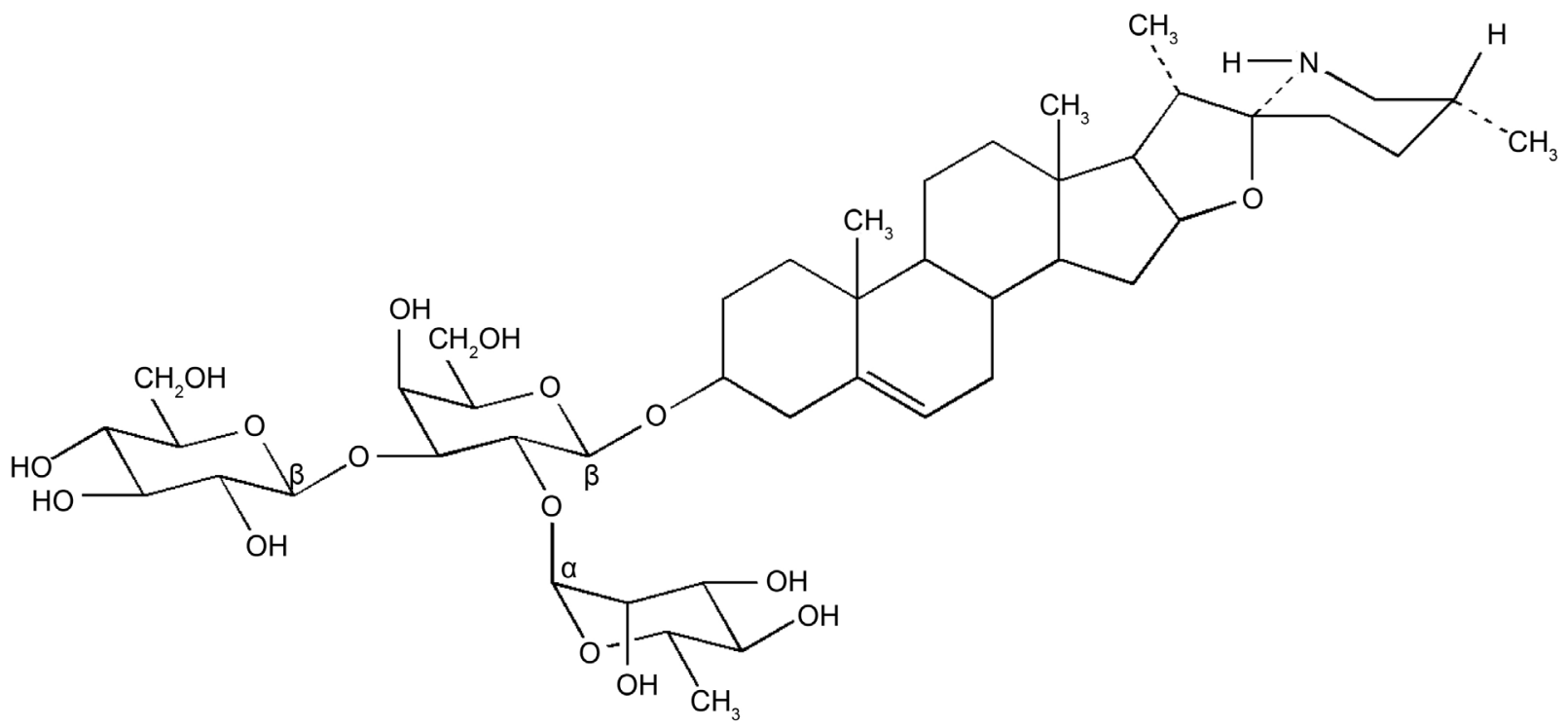

solasonine

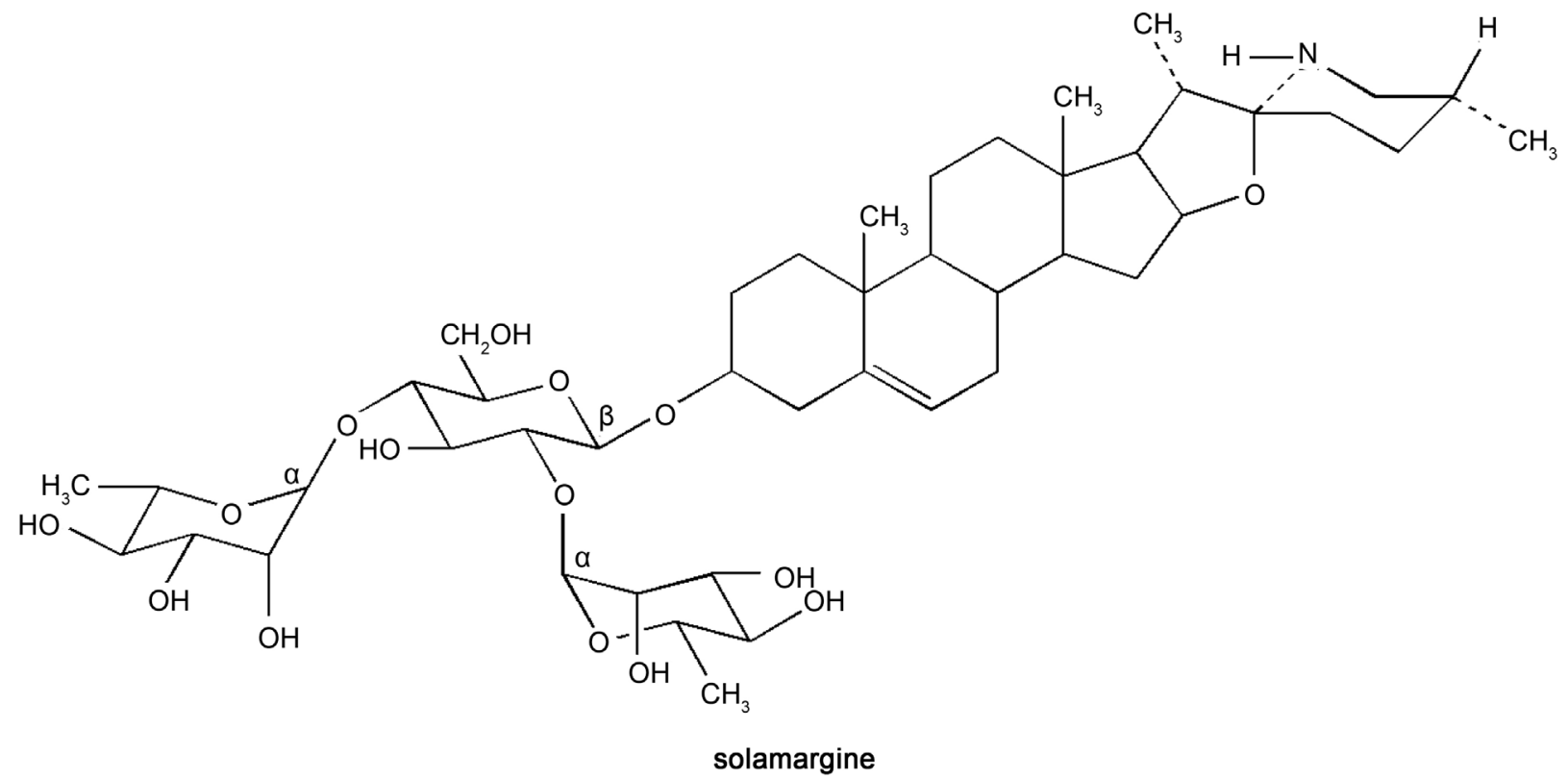

Figure 1. BEC is a standardized mixture of sugar-bound solasodine. The two main glycoalkaloids are solasonine and solamargine. All of the glycoalkaloids are made up of the steroid solasodine and one or more of the sugars rhamnose, glucose or galactose. 
The sugar moiety of the triglycoside solamargine is:

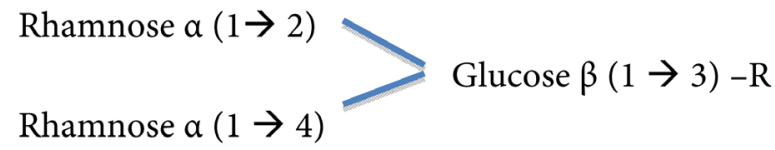

One of its precursor molecules diglycoside is:

Rhamnose $\alpha(1 \rightarrow 2)=$ Glucose $\beta(1 \rightarrow 3)-\mathrm{R}$

Another is:

Rhamnose $\alpha(1 \rightarrow 4) \Longrightarrow$ Glucose $\beta(1 \rightarrow 3)-\mathrm{R}$

Its precursor molecule monoglycoside is:

Glucose $\beta(1 \rightarrow 3)-\mathrm{R}$

$\mathrm{R}=$ Solasodine

Figure 2 shows the chemical structure of Solasodine.

In the early studies the microscopic morphological features of cancer cell death e.g. membrane blebbing, cell shrinkage, chromatin condensation, DNA fragmentation and apoptotic bodies determined that cell death was by apoptosis (Figure 3) [2] [6].

Newer techniques which are currently commercially available such as Tunel and DNA damage assays, Caspase detection assays, Mitochondrial permeability assays, Annexin V detection assays, Life/death stains and Cytotoxicity test kits have confirmed the earlier studies of 1990 [6]-[27].

Figure 4 illustrates an example of the analysis by Annexin V/PI assay and flow cytometry, indicating the cellular death events. This figure shows that SM increased apoptosis over tenfold more in malignant to normal cells [7].

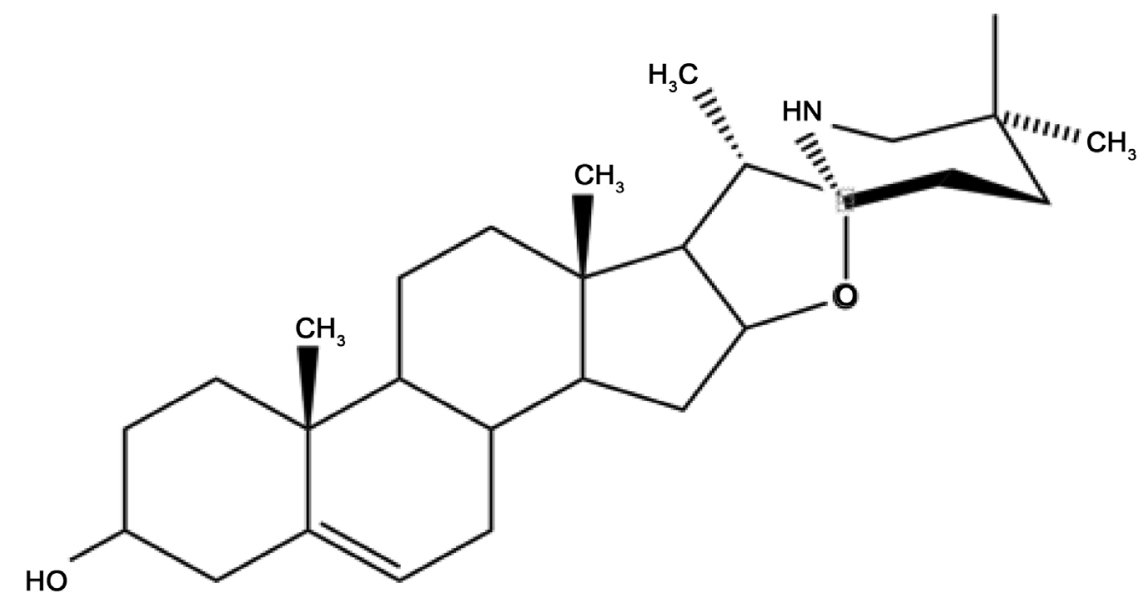

Figure 2. The chemical structure of the steroidal alkaloid solasodine. 


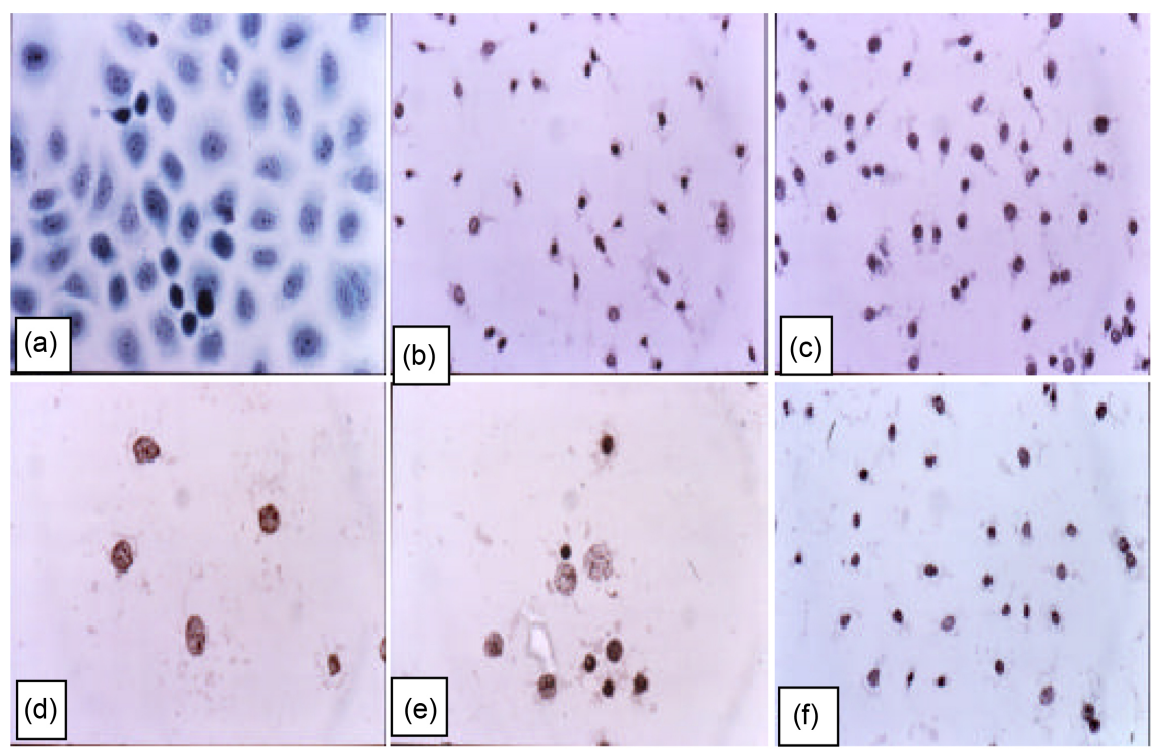

Figure 3. Untreated ovarian cancer cells, the cells are all viable (a). BEC causes the cytoplasm of the cancer cells to undergo dissolution, the nuclei contract and become dark staining (b), nuclei then enlarge (c), the chromatin (contents of nucleus) clumps (d) and finally the nuclei disintegrate (e). Only cellular debris is left after the interaction of the cancer cells with BEC (f). This cell death is characteristic of apoptosis, which is also known as programmed cancer cell death. The cells were fixed and examined microscopically $(\times 1000)$ by the Papanicolaou method [2].

\section{Melanoma Cells}
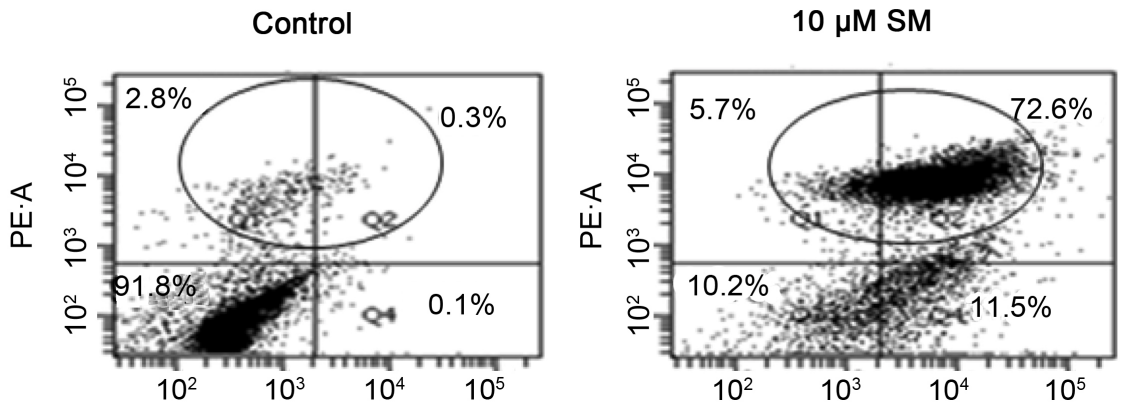

Normal cells
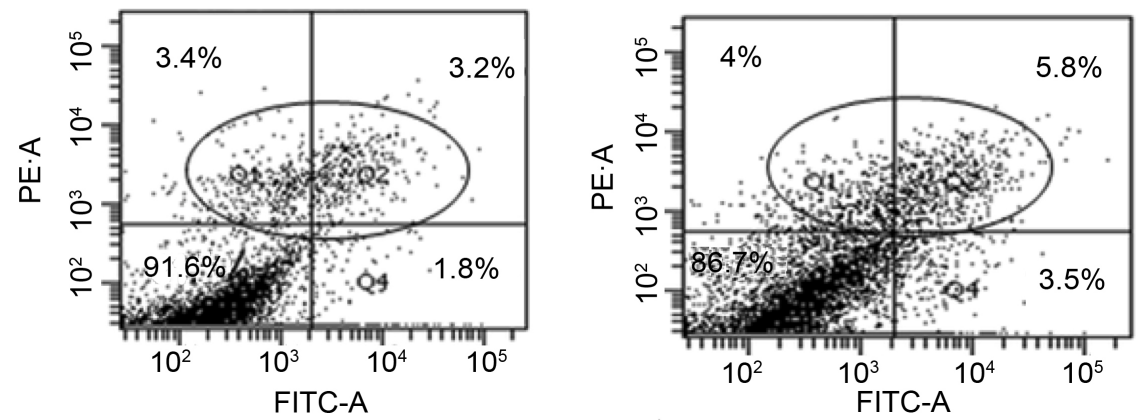

Figure 4. Flow cytometry analysis show that solamargine increased apoptosis over tenfold more in malignant to normal cells. $10 \mu \mathrm{M}$ solamargine treatment for $2 \mathrm{~h}$ selectively caused massive cellular death of primary melanoma cells, which was over tenfold more, than that detected in normal cells [7]. 
A large number of investigators have now reported that these SGs induce cell cycle arrest and apoptosis in a wide variety of cancer cells, such as, ovarian cancer, basal cell carcinoma, squamous cell carcinoma, melanoma, colorectal cancer, bladder cancer, oral epidermoid carcinoma, breast cancer, myelogenous leukemia, prostate cancer, liver cancer, lung cancer, endometrial cancer, pancreatic cancer, gastric carcinoma, renal cancer, uterine cancer, mesothelioma, glioblastoma and osteosarcoma [6]-[27].

Compared with many existing clinically used cytotoxic drugs, SGs have interesting superior properties, which have been elucidated by understanding their modes of actions.

\section{Pharmacodynamics}

\section{Specificity}

Rhamnose conjugated to the aglycone solasodine, plays a key role in recognizing and binding to specific endogenous endocytic lectins (EELs) rhamnose binding protein (RBP) receptors. Rhamnose is a plant sugar and is normally not present in the human body [2]. The RBP receptors have been identified and characterized [28]. The abundance of these receptors is much higher in cancer cells as opposed to normal noncancerous cells [2] [6] [7] [9] [28] [29] [30].

With lectins, the recognition of rhamnose is highly specific and is comparable to the antigen-specificity of antibodies or the substrate-specificity of enzymes [6] [9].

The numbers of RBP receptors on the various cell types range from 500 10,000 per cell with an affinity constant of $1.5 \times 10^{-6} \mathrm{M}$ and a molecular weight of $67 \mathrm{kDa}$. Different cell populations of specific cancers express a single type of receptor in a wide variety of cancer cell lines.

Figure 5 shows that there are two types of binding of BEC, related to receptor affinity and numbers of receptors per cell, on cancer cells [28].

Competitive inhibition studies of BEC with rhamnose in cancer cells have revealed the importance of the presence of unbound rhamnose in formulations. For example, Figure 6 shows that increasing concentrations of BEC resulted in decreasing melanoma cell survival, with $\mathrm{ED}_{50}$ of $12 \mathrm{microgram} / \mathrm{mL}$ of $\mathrm{BEC}$ and $\mathrm{LD}_{100}$ of approximately 20 microgram $/ \mathrm{mL}$ of BEC. When $5 \mathrm{mM}$ rhamnose is co-administered with the BEC to the melanoma cancer cells, virtually all the melanoma cells survived [6] [9] [28].

These observations were confirmed in whole animal studies shown in Figure 7. Mice inoculated with the cancer S180 died in 2 - 3 weeks. Four doses of BEC at $8 \mathrm{mg} / \mathrm{kg}$ resulted in $100 \%$ survival of $S 180$ inoculated mice. Increasing concentrations of free rhamnose, administered intraperiotoneally into BEC-treated mice inoculated with S180 cells reduced the efficacy of BEC [6] [29].

Fluorescence imaging analysis of a synthesized biotinylated-rhamnose probe has visualized the expression of RBP receptors on cancer cells. Using this technique it was shown that 100 micro Molar of free rhamnose completely blocked 


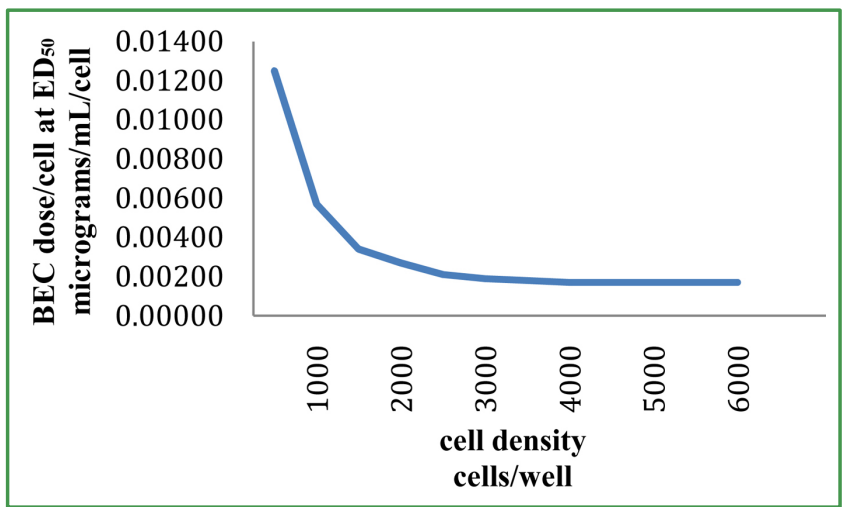

Figure 5. BEC dose/cell at $\mathrm{ED}_{50}$ vs. cell density of 16 different cell lines. Two distinct regions are discernable. Cell densities of 1500 cells and less show that receptor affinity is a major determinant of cytotoxicity. Cell density above 1500 cells denotes a lower number of receptors per cell or slower toxicity [28].

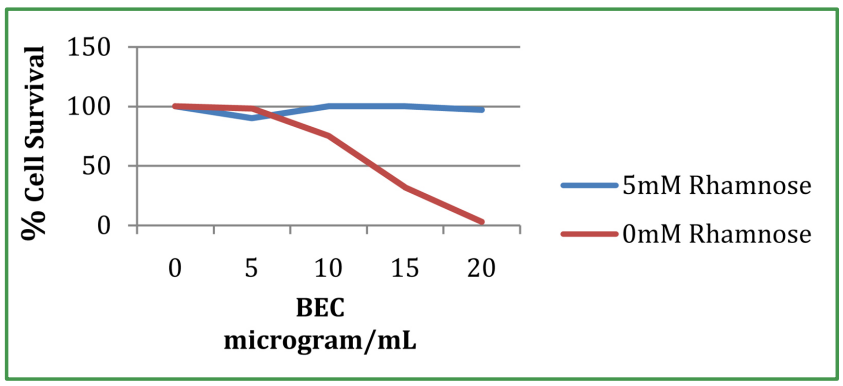

Figure 6. Effect of solasodine glycosides (BEC) and rhamnose on in Vitro A2058 melanoma cells [9].

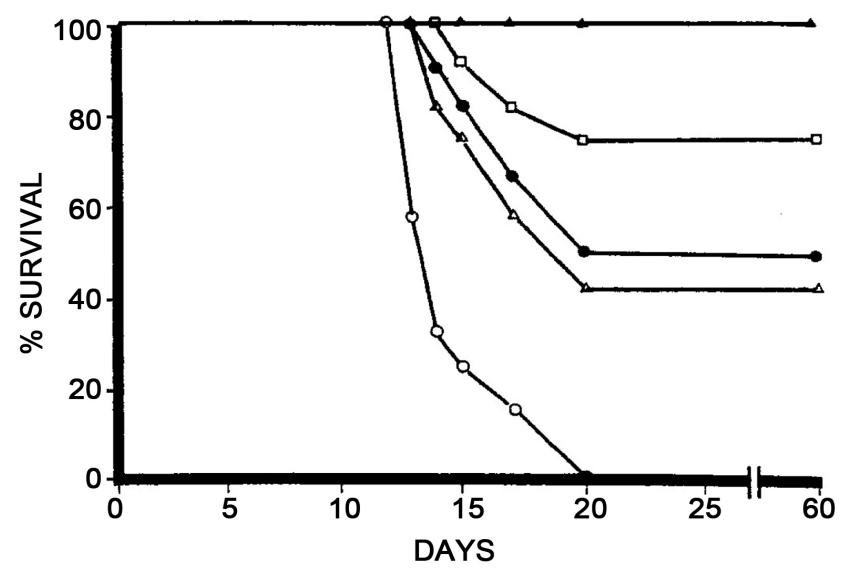

Figure 7. Effect of solasodine glycosides (BEC) and rhamnose on mouse survival with S180. - 0 - Untreated S180; $-\Delta$ - 4 doses BEC 8 $\mathrm{mg} / \mathrm{kg}+$ rhamnose $15 \mathrm{mg} / \mathrm{kg}$; - - 4 doses BEC $8 \mathrm{mg} / \mathrm{kg}+\mathrm{rham}$ nose $10 \mathrm{mg} / \mathrm{kg}$; - - 4 doses BEC $8 \mathrm{mg} / \mathrm{kg}+$ rhamnose $5 \mathrm{mg} / \mathrm{kg}$; - $\boldsymbol{\Delta}$ - 4 doses BEC $8 \mathrm{mg} / \mathrm{kg}[6]$.

the binding of the probes to cancer cells (Figure 8) [28] [29] [30].

At a clinical level the presence of very low concentrations of rhamnose imparts 


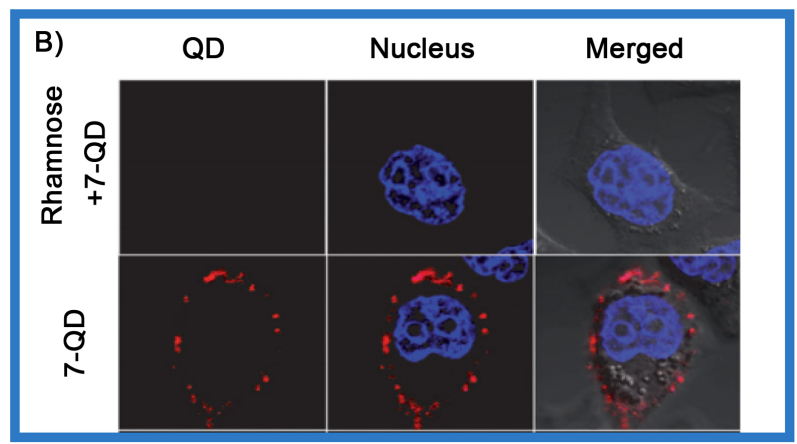

Figure 8. Confocal microscopic view of rhamnose-QD probe (representing SM) localized on the cell surface of human squamous cell carcinoma (KB) cells. The binding of the probe was blocked by rhamnose. Confocal microscope image of $\mathrm{KB}$ cells labelled by probe (red) and Hoechst stain (blue) [30].

inhibitory properties to the efficacy of BEC or SM formulations when treating terminal tumors and skin cancers [29] [31].

Unconjugated solasodine and solasodine conjugated with glucose did not bind to cancer cells on their RBP receptors and consequently, at equimolar concentrations, had no significant anticancer effects. On the other hand, SM and solasodine mono-rhamnoside expressed strong anticancer activities [29] [30], indicating the importance of rhamnose in the pharmacodynamics of SM and BEC.

Different cancer cells expressed different levels of RBP receptors. Higher numbers of rhamnose moieties in the structure of rhamnosides or increased RBP receptor expression on cell surfaces mediate more effective cancer cell elimination [30]. These observations support the data in Figure 5 showing that there are two types of binding of SM and BEC, related to receptor affinity and numbers of receptors, per cell.

SM contains two molecules of rhamnose, whereas, SS contains one molecule of rhamnose. At equimolar concentrations, on average, SM is 9 times more potent than SS and 19 times more potent than the mono-and-di glycosides of solasodine [32]. When calculated, the contribution of anticancer activities in BEC is $86 \%$ for SM, $9 \%$ for SS and 5\% for mono- and diglycosides of solasodine. Although the aglycone solasodine does not bind to the RBP receptor on the cancer cells, solasodine can also penetrate cancer cells by diffusion causing apoptosis [2] [6] [9] [26] [33] [34] [35] [36] [37]. The observed anticancer activities of solasodine are less than those observed with equivalent concentrations of solasodine rhamnosides [2] [6] [9] [26] [30].

After binding of the solasodine rhamnosides to their specific RBP receptors, the solasodine rhamnosides are internalized into the cancer cell by receptor-mediated endocytosis through endosomes and ultimately in the lysosomes. SM then induces an early lysosomal rupture, subsequently mitochondrial damage including mitochondrial permeabilization occurs. Consequently, the pro-apoptotic Bax and Bak proteins are increased, but the anti-apoptotic Bcl-2 
and $\mathrm{Bcl}-\mathrm{x}$ proteins are decreased at the transcriptional and translational phases. Caspase- 9 and Caspase- 3 are activated during these processes, resulting in apoptosis [7] [11] [14] [15] [16] [17] [18] [38] [39] [40] [41] [42]. It is important to note that the ratio rather than the amount of pro-apoptotic versus anti-apoptotic proteins determine whether apoptosis proceeds.

Studies have also shown that SM and BEC affect the extrinsic death pathway in cancer cells by up-regulating the expressions of external death receptors such as tumor necrosis factor receptor 1 (TNFR-1) and 6 (TNFRSF6 or Fas receptor), TNFR-1-associated death domain (TRADD) and Fas-associated death domain (FADD) [6] [9] [16] [41].

At a clinical level compelling evidence of specificity of BEC towards cancer cells was shown with skin cancer treatments [4] [5] [43]-[64].

The BEC-containing cream formulation Curaderm ${ }^{\mathrm{BEC} 5}$ seeks and destroys skin cancer cells whilst normal skin cells replace the dead cancer cells DURING therapy. This indicates that BEC only affects cancer cells but not normal cells. In addition, BEC locates and eliminates cancer cells at the microscopic level. Visually, during Curaderm ${ }^{\mathrm{BEC} 5}$ therapy, the treated skin cancer lesion appears to, initially become larger until the cancer cells are eliminated, followed by reduction of the skin lesions until complete removal of the skin cancer cells and replacement with normal cells occurs.

Figure 9 and Figure 10 show the persuasive graphic and pictorial events of the treatment of a basal cell carcinoma [57]. The specificity of BEC towards cancer cells is self-evident and clinically confirms the cellular biochemical pharmacodynamics.

\section{Efficacy}

BEC and SM exhibit much higher cytotoxic effects on cancer cells when compared with a number of currently used antineoplastic agents such as vinblastine,

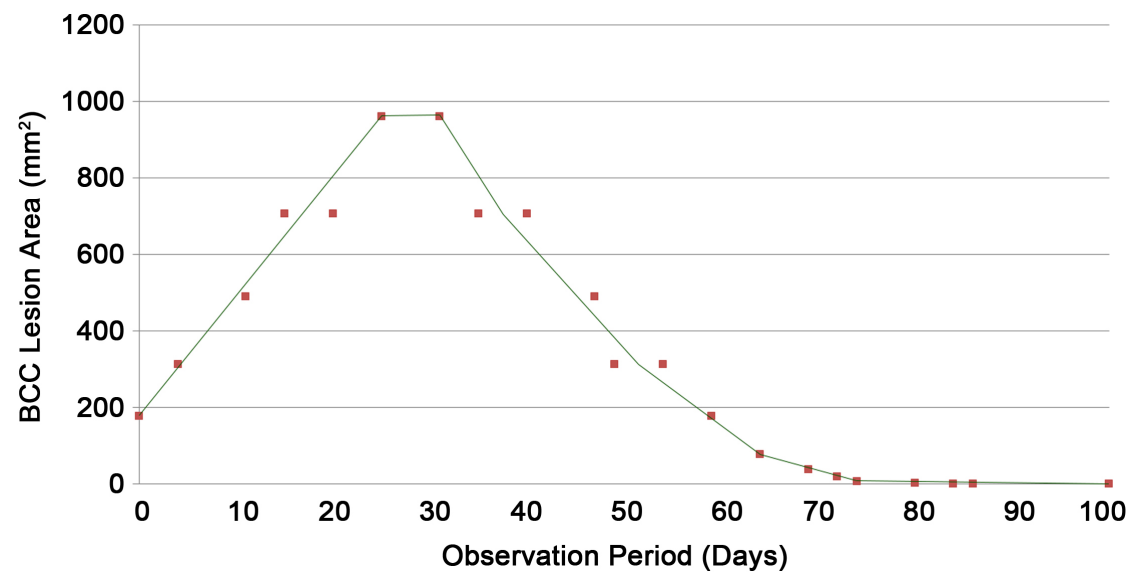

Figure 9. Curaderm ${ }^{\mathrm{BEC} 5}$ therapy caused an immediate change in BCC lesion size and after 30 days treatment, peaked at over a 4 -fold increase in size. Continuous treatment after 30 days resulted in a decrease in lesion size and complete removal of the BCC was attained after 86 days of Curaderm ${ }^{\mathrm{BEC} 5}$ therapy [57]. 

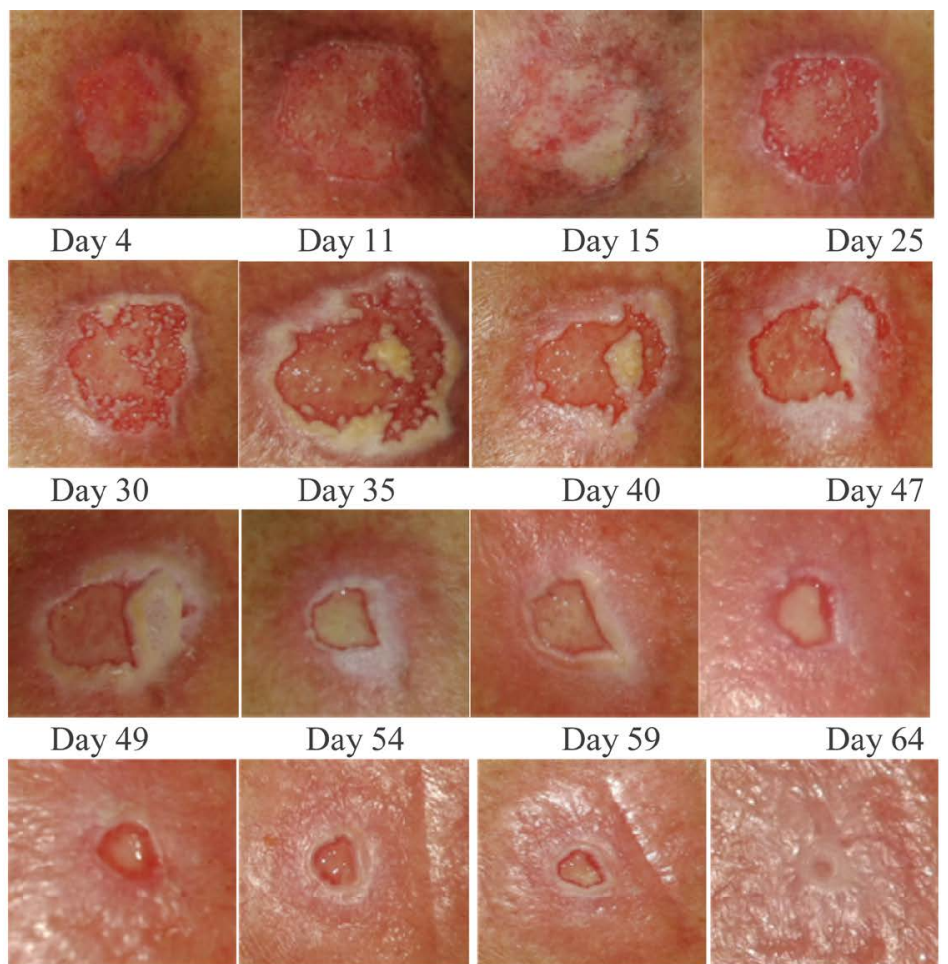

Day 59

Day 64
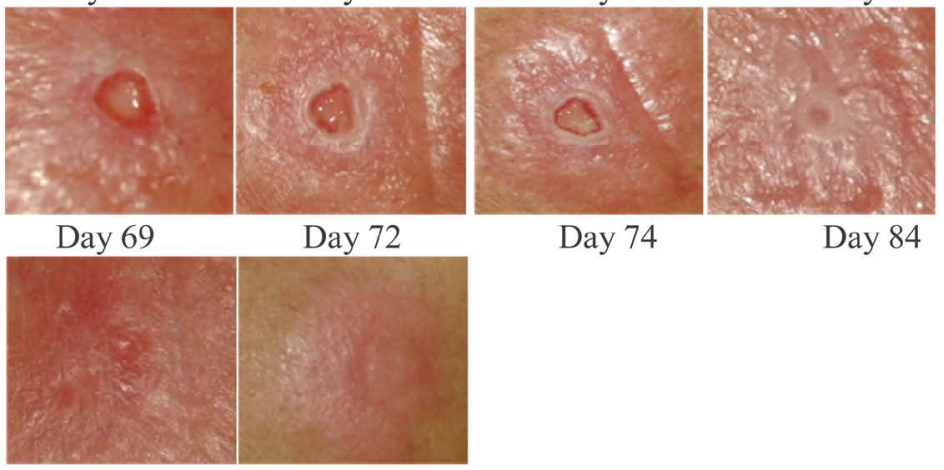

Day 86

Day 100

Figure 10. Appearances of BCC lesion during and after Curaderm ${ }^{\mathrm{BEC} 5}$ therapy. Curaderm ${ }^{\mathrm{BEC} 5}$ was applied 3 times daily at a dose of $0.1 \mathrm{~g}$ cream and covered with micropore paper tape occlusive dressing. The indicated days refer to the treatment periods. Cancer cells were being eliminated and replaced with normal epidermal skin cells during treatment. Treatment was stopped only after the original BCC lesion had healed (day 86) [57].

camptothecin, vincristine, methotrexate, cisplatin, 5-fluorouracil, gemcitabine, epirubicin, cyclophosphamide, taxol and doxorubicin [6] [9] [37].

The absolute concentrations of these drugs to obtain similar efficacy as BEC and SM are in the order of 6 - 40 times higher [6] [9].

The higher efficacy of SM compared to taxol, cisplatin and gemcitabine when treating lung cancer cells are illustrated in Figure 11.

Moreover, the therapeutic index (TI) $\mathrm{LD}_{50} / \mathrm{ED}_{50}$ is much higher for BEC and SM than for established drugs [6] [9]. The TI, also referred to as therapeutic ratio, is a comparison of the amount of a therapeutic agent that causes the therapeutic effect to the amount that causes toxicity. The $\mathrm{LD}_{50}$ is defined as the dose of the antineoplastic agent to kill $50 \%$ of normal noncancerous cells, whereas, the $\mathrm{ED}_{50}$, also known as $\mathrm{IC}_{50}$, is defined as the dose of the antineoplastic agent to 


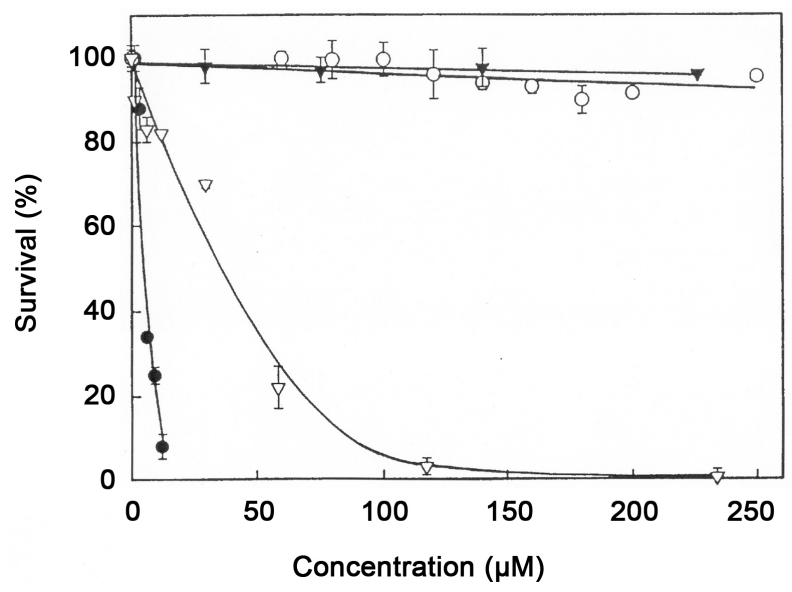

Figure 11. The effect of solamargine - $\bullet-$, taxol $-\nabla$-, cisplatin $-\bigcirc-$, or gemcitabine $-\nabla$ - on the survival of lung cancer cells [6].

kill $50 \%$ of the cancer cells. The larger the TI, the more effective and safer the drug is. Values of TI for BEC and SM are in the range of 2.6 to 4.0 as shown in cell culture studies [6] [9] and in whole animal studies [3]. For the indication of cancer treatment, these values are considered to be very good. High TI with BEC and SM translates to high safety margins. With conventional antineoplastic agents the TI is much narrower, often less than 1, which explains the toxic effects encountered by patients on such therapies. Compounded to this, with current antineoplastics, systemic exposure after standard doses of cytotoxic drugs can vary two to ten-fold between patients leading to unpredictable toxicity and variable antineoplastic effects. These problems are increased exponentially when mono chemotherapy is replaced with combination chemotherapy.

\section{Multidrug-Resistance (MDR)}

MDR is the mechanism by which many cancers develop resistance to chemotherapy drugs, resulting in minimal cell death and the expansion of drug-resistant tumors. MDR is a major factor in the failure of many forms of chemotherapy with cancer treatment.

One important mechanism of MDR involves the multidrug transporter, P-glycoprotein (Pgp), which confers upon cancer cells the ability to resist lethal doses of certain cytotoxic drugs by pumping the drugs out of the cells and thus reducing their cytotoxicity.

BEC and SM are chemosensitizing agents against various drug resistant-cancers and defeat MDR in cancer cells. SM effectively triggers apoptosis in MDR tumor cells, and is associated with actin disruption of MDR 1 gene expression [64] [65] [66].

Low concentrations of BEC are required to dysfunction the Pgp and subsequently allows sudden efficacy of previously ineffective drugs therapies, for example MDR breast and lung cancer [1] [2] [6] [12] [39] [40] [41] [42]. The cy- 
totoxicity of BEC and SM against MDR tumor cells is nearly equal or even more potent than against the corresponding parent cell lines [6] [9].

\section{Metastasis}

Cancer metastasis may be defined as spreading of primary tumor cells and the outgrowth of secondary tumors at distant sites. Metastatic tumor cells possess several distinctive characteristics; they undergo epithelial-mesenchymal transition (EMT) and become invasive, become resistant to apoptosis and anoikis, and acquire the ability to disseminate and colonize secondary sites. SM inhibits the migration and invasion viability of HepG2 cells by blocking EMT [33] [34] [38].

Matrix metalloproteinases (MMPs) are a large group of zinc-dependent proteinases responsible for cleaving and rebuilding extracellular matrix and basement membrane. MMP-2 and MMP-9 contribute to the establishment of metastasis-prone sites at tumor-distant organs [67]. SM suppresses the invasive capacity of HepG2 cells by downregulation of MMP-2 and MMP-9 expressions and activities [68].

Anti-metastatic activity of solasodine has also been reported with ovarian cancer cells [26], lung cancer cells [33] and human colorectal cancer cells [34]. Solasodine selectively and effectively inhibits the growth of metastatic and primary melanoma cells with minimum effect on normal and benign melanoma cells [7]. SM induces apoptosis in melanoma cell lines [2] [6] [9] and inhibits and eliminates melanoma in vivo [48] [49].

\section{Immunological Effects}

The natural capacity of the immune system to detect and destroy abnormal cells may prevent the development of many cancers. However, cancer cells are sometimes able to avoid detection and destruction by the immune system.

Immunotherapy is a rapidly advancing field of cancer immunology. These therapies increase the strength of the immune responses against tumors by either stimulation of the activities of specific components of the immune system or counteract signals produced by cancer cells that suppress the immune responses.

BEC stimulates lasting immunity against cancer [69]. The mode of action of BEC to produce immunity is not known. It has been speculated that BEC may release antigenic peptides (epitopes) of cancer cells, which may be unexposed on the cancer cells before the interaction with BEC. Consequently, these epitopes may be present in appropriate forms to induce immunity [69].

Stimulation of innate immunity using unmethylated CpG-containing oligodeoxynucleotides when combined with BEC treatment slow tumor growth and provides a survival benefit with malignant mesothelioma [70].

$\mathrm{BEC}$ is effective in treating herpes simplex, herpes zoster and genital herpes in humans. BEC exhibits rapid activity against these viruses, and follow-up of the treated patients for one year showed no recurrences, whereas, in control groups, 
recurrences of herpes infection ranged from one to six months, indicating some longer term immunity induced by BEC. Interestingly, the antiviral mode of action of BEC is similar to the antineoplastic mode of action of BEC with cancer cells [71] [72].

\section{BEC Kills Dormant Cancer Cells}

Most chemotherapy drugs preferentially affect rapidly proliferating cells, whether these cells are cancer cells or normal cells. For this reason conventional chemotherapies cause many side effects such as, effects on the circulatory and immune systems, nervous and muscular systems, digestive system, integumentary system, sexual and reproductive systems, excretory system, skeletal system and psychological and emotional effects.

When cancer cells are dormant, chemotherapy drugs have lesser efficacy on cancer cells and higher toxicity, relative to normal cells. These effects are caused by non-specificity of the drugs towards cancer cells. Contrary to conventional chemotherapy, BEC and SM target cancer cells and not normal cells. The interaction of BEC and SM with specific RBP receptors, which are more abundant on cancer cells, and the sequelae of apoptosis of these cancer cells, result in the safe elimination of these targeted cells, whether the cells are proliferating or not.

\section{Toxicology}

Considerable information is available on the toxic effects of glycoalkaloids in the published literature. However, as BEC and SM relate to solasodine and its glycosides, the predominant glycoalkaloids in eggplant, information drawn from the literature show that at anticancer therapeutic concentrations these specific substances are safe.

Animal studies in mice, rats, dogs, horses and humans have determined that, at antineoplastic therapeutic doses, BEC and SM are safe [4] [5] [32] [43] [45]-[52] [54]-[59] [73] [74] [75] [76].

Genotoxicity studies in five tester strains of Salmonella typhimurium have shown that there was no evidence of mutagenicity in response to BEC and SM in any of the tester strains [6] [9] [74].

No data, specific to carcinogenicity are available. However, the widespread existence of BEC in the diet of humans and the low concentration of BEC to induce therapeutic efficacy provide some assurance that carcinogenicity is unlikely to be a significant concern. Furthermore, efficacy studies of BEC in animals and humans that were followed up for extended periods showed no evidence of carcinogenicity [3] [4] [5] [6] [9] [74].

Studies of reproductive effects including teratogenicity of BEC showed that in hamsters, extracts from eggplant did not cause an increase in the number of deformed litters [77]. Similarly, there were no teratogenic and reproductive effects of BEC in mice [3] [6] [9]. BEC has been shown to immobilize human sperm cells [2] [6] [47]. 


\section{Pharmacokinetic Parameters Are Conducive to Clinical Applications}

The pharmacokinetics of SM in rats, dogs and humans has been reported. The plasma half-life (T1/2) of SM in rats ranges from 1.28 to $3.54 \mathrm{~h}$, with a clearance of 3.18 to $4.10 \mathrm{~L} / \mathrm{kg} / \mathrm{h}$, and a volume of distribution 15.68 to $20.16 \mathrm{~L} / \mathrm{kg}$ [74] [78].

Figure 12 illustrates the time course response of the concentration of SM after infusion of a dose of $0.5 \mathrm{mg} / \mathrm{kg}$ of SM with an infusion rate of $20 \mathrm{~mL} / \mathrm{kg} / \mathrm{h}$ over a period of 30 minutes in Beagle dogs, the plasma T1/2 of SM is 2.3 - $3.4 \mathrm{~h}$ [74].

Phase 1 human clinical trials of Coramsine (1:1 mixture of SM and SS) in patients with advanced solid tumors have been reported [79]. The range of doses studied was from 0.75 to $3.0 \mathrm{mg} / \mathrm{kg} /$ day.

Dose-limiting hepatotoxicity at doses above $1.0 \mathrm{mg} / \mathrm{kg} /$ day over 2 hours, or $1.5 \mathrm{mg} / \mathrm{kg} /$ day over 4 hours were observed.

The dose-limiting toxicities (DLT) were grade III/IV transaminitis, with grade I-III increases in bilirubin and grade I-II creatinine. Hepatotoxicity was maximal at days 3 - 5, resolved over 10 - 21 days and was clinically asymptomatic apart from grade I-II fatigue, and was not cumulative. No myelosuppression or other serious drug-related toxicity was recorded. Activity of 1:1 mixture of SM and SS against resistant solid tumors in patients was observed [79].

The maximum tolerated dose (MTD) was exceeded at a dose of 2.25 $\mathrm{mg} / \mathrm{kg} /$ day over 24 hours infusion.

Figure 13 illustrates the disposition of SM at two doses, $1.5 \mathrm{mg} / \mathrm{kg}$ and 3.0 $\mathrm{mg} / \mathrm{kg}$ Coramsine, corresponding to $0.75 \mathrm{mg} / \mathrm{kg}$ and $1.5 \mathrm{mg} / \mathrm{kg} \mathrm{SM}$, over an intravenous infusion period of 4 hours. The dose increase in Cmax and AUC parameters with increasing doses are evident.

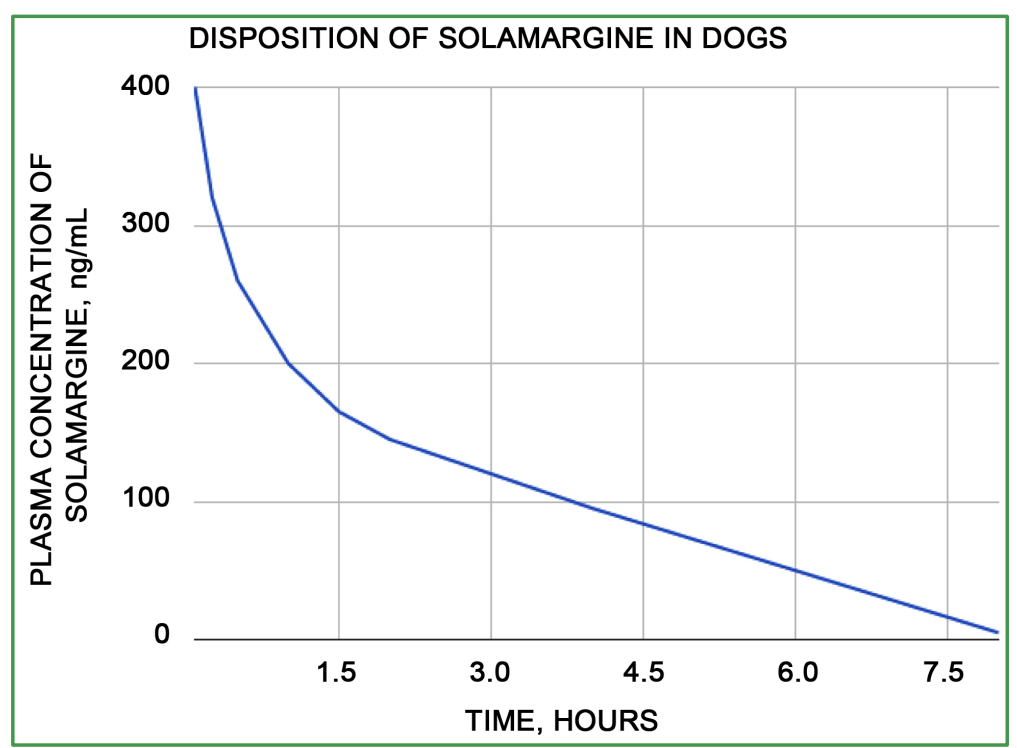

Figure 12. Disposition of SM following a 30 minute intravenous infusion. Dogs (one male and one female) were infused with SM at a dose of $0.5 \mathrm{mg} / \mathrm{kg}$ in the form of $1: 1$ mixture of SM and SS $(1 \mathrm{mg} / \mathrm{kg})$ over 30 minutes at an infusion rate of $20 \mathrm{~mL} / \mathrm{kg} / \mathrm{h}$ [74]. 


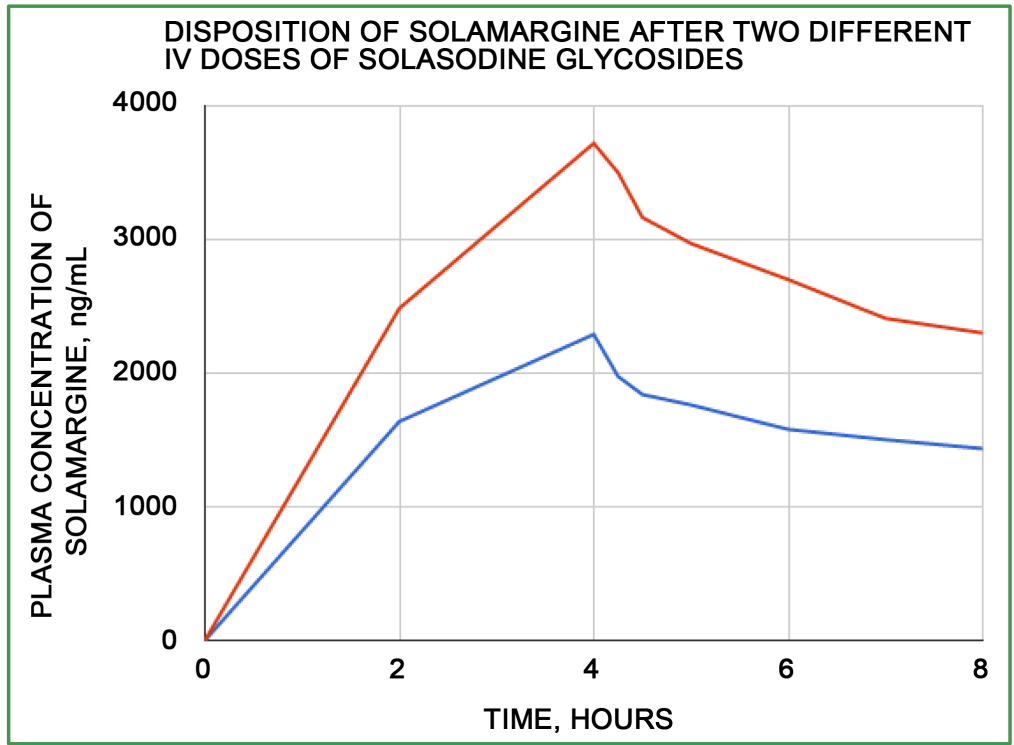

Figure 13. Disposition of SM following a 4 hour intravenous infusion of 1.5 $\mathrm{mg} / \mathrm{kg}$ $(\mathrm{n}=8)$, and $3.0 \mathrm{mg} / \mathrm{kg}$ $(\mathrm{n}=2)$ Coramsine [78].

Pharmacokinetic parameters for SM was linear across the narrow range of doses studied. Peak plasma concentrations of SM exceeded active in vitro concentrations of SM (higher than $2000 \mathrm{ng} / \mathrm{mL}$ ). Dose increase resulted in increases in Cmax and AUC. The sampling schedule did not completely cover the pharmacokinetic profile with the last sample collected only 4 hours after completion of the infusion. The implication is that the terminal phase was not well defined and this has some bearing on the interpretation of pharmacokinetic parameters that are derived from definition of the terminal phase. Notwithstanding such limitations, the calculated apparent elimination T1/2 was $8.40 \pm 2.0 \mathrm{~h}$ with a clearance of $3.0 \pm 0.7 \mathrm{~L} / \mathrm{h}$.

Plasma protein binding for SM ranges from 76.7\% - 96.3\% [6].

The primary aim of the phase 1 study was to determine the safety-toxicity profile and the maximum tolerated dose of the study medication in patients with advanced solid tumors. Efficacy response to treatment was not a primary endpoint of the study.

Nevertheless, radiological improvement of the tumors and reduction of tumor markers in some patients were observed [79]. It was concluded that 1:1 ratio of SM and SS can be given to cancer patients safely. The dose limiting toxicity was transient reversible elevation of hepatic transaminases. A dose schedule that should result below the MTD, of $1.5 \mathrm{mg} / \mathrm{kg} /$ day over 4 hours for 5 days, every 2 weeks was proposed for further clinical trials [79].

\section{Conclusion}

BEC, solamargine, solasodine and other related alkaloids trigger cancer cell death by two distinct mechanisms, the lysosomal-mitochondrial mediated apoptosis pathway and the death receptor-mediated apoptosis pathway. The 
carbohydrate moiety of these steroidal alkaloids plays a key role in expressing higher specificity and efficacy with their antineoplastic actions. These alkaloids do not fall in the class of multi-drug-resistance with cancer cells, which is clinically of great importance. Also of great importance are their anti-metastatic properties. Published preclinical and clinical studies with solasodine and its glycosides, including BEC and SM, are appearing at very high rates in the literature. Compelling evidence is now available showing that the safety, pharmacokinetics and numerous advantages in the pharmacodynamics of these components, deserve implementation of further multicentre clinical studies in patients suffering with primary and systemic cancers. Already, at a clinical level, BEC is a highly efficacious, safe and successful topical formulated cream treatment for skin cancer. The pathway to extensive clinical application of these very promising antineoplastic agents is now cleared.

\section{Prospective}

The promise of these natural drugs to combat cancer for the reasons outlined in this communication is exciting. Even more appealing are the possibilities of modifying these solasodine glycoside components to yield higher specificities with superior efficacies.

RBP agonist may be constructed to specifically adapt to interact, bind, and be internalized into cancer cells to prevent cell growth or division or cause cell death. These RBP agonist-agent conjugates may be selected from groups of existing chemotherapeutic agents to induce much higher specificities and lower toxicities.

\section{References}

[1] Cham, B.E. and Wilson, L. (1987) HPLC of Glycoalkaloids from Solanum sodomaeum. Planta Medica, 53, 59-62. https://doi.org/10.1055/s-2006-962621

[2] Daunter, B. and Cham, B.E. (1990) Solasodine Glycosides. In Vitro Preferential Cytotoxicity for Human Cancer Cells. Cancer Letters, 55, 209-220. https://doi.org/10.1016/0304-3835(90)90121-D

[3] Cham, B.E., Gilliver, M. and Wilson, L. (1987) Antitumor Effects of Glycoalkaloids Isolated from Solanum sodomaeum. Planta Medica, 53, 34-36. https://doi.org/10.1055/s-2006-962612

[4] Cham, B.E. and Meares, H.M. (1987) Glycoalkaloids from Solanum sodomaeum Are Effective in the Treatment of Skin Cancers in Man. Cancer Letters, 36, 111-118. https://doi.org/10.1016/0304-3835(87)90081-4

[5] Cham, B.E. and Daunter, B. (1990) Topical Treatment of Pre-Malignant and Malignant Skin Cancers with Curaderm. Drugs of Today, 26, 55-58.

[6] Cham, B.E. (2013) Inspired by Nature, Proven by Science. The New Generation Cancer Treatment That Causes Cancer Cells to Commit Suicide. Colorite Graphics Printers, Port Vila, $264 \mathrm{p}$.

[7] AlSinani, S.S., Eltayeb, E.A., Coomber, B.L. and Adham, S.A. (2016) Solamargine Triggers Cellular Necrosis Selectively in Different Types of Human Melanoma Cancer Cells through Extrinsic Lysosomal Mitochondrial Death Pathways. Cancer 


\section{Cell International, 16, 287-294.}

[8] Hu, K., Kobayashi, H., Dong, A., Jing, Y., Iwasaki, S. and Yao, X. (1999) Antineoplastic Agents III: Steroidal Glycosides from Solanum nigrum. Planta Medica, 65, 35-38. https://doi.org/10.1055/s-1999-13958

[9] Cham, B.E. (2013) Drug Therapy: Solamargine and Other Solasodine Rhamnosyl Glycosides as Anticancer Agents. Modern Chemotherapy, 2, 33-49. https://doi.org/10.4236/mc.2013.22005

[10] Cham, B.E. (1994) Solasodine Glycosides as Anti-Cancer Agents: Pre-Clinical and Clinical Studies. Asia Pacific Journal of Pharmacology, 9, 113-118.

[11] Vijayan, P., Vinod, K.S., Dhanaraj, S.A., Badami, S. and Suresh, B. (2002) In Vitro Cytotoxicity and Anti-Tumorproperties of the Total Alkaloid Fraction of Unripe Fruits of Solanum pseudocapsicum. Pharmacology Biology, 40, 456-460. https://doi.org/10.1076/phbi.40.6.456.8444

[12] Ono, M., Nishimura, K., Suzuki, K., Fukushima, T., Igoshi, K., Yoshimitsu, H., Ikeda, T. and Nohara, T. (2006) Steroidal glycosides from the underground parts of Solanum sodomaeum. Chemical and Pharmaceutical Bulletin, 54, 230-233. https://doi.org/10.1248/cpb.54.230

[13] Nakamura, T., Komori, C., Lee, Y., Hashinoto, F., Yahara, S., Nohara, T. and Ejina, A. (1996) Cytotoxic Activities of Solanum Steroidal Glycosides. Biological and Pharmaceutical Bulletin, 19, 564-566. https://doi.org/10.1248/bpb.19.564

[14] Liu, L.F., Liang, C.H., Shiu, L.Y., Lin, W.L., Lin, C.C. and Kuo, K.W. (2004) Action of Solamargine on Human Lung Cancer Cells-Enhancement of the Susceptibility of Cancer Cells to TNFs. The FEBS Letters, 577, 67-74.

[15] Lee, K.R., Kozukue, N., Han, J.S., Park, J.H., Chang, E.Y., Back, E.J., Chang, J.D. and Friedman, M. (2004) Glycoalkaloids and Metabolites Inhibit the Growth of Human Colon (HT29) and Liver (HepG2) Cancer Cells. Journal of Agricultural and Food Chemistry, 52, 2832-2839. https://doi.org/10.1021/jf030526d

[16] Kuo, K.W., Hsu, S.H., Li, Y.P., Lin, W.L., Liu, L.F., Chang, L.C., Lin, C.N., Lin, C.C. and Sheu, H.M. (2000) Anticancer Activity Evaluation of the Solanum Glycoalkaloid Solamargine. Triggering Apoptosis in Human Hepatoma Cells. Biochemical Pharmacology, 60, 865-1873. https://doi.org/10.1016/S0006-2952(00)00506-2

[17] Chang, L.C., Tsai, T.R., Wang, J.J., Lin, C.N. and Kuo, K.W. (1998) The Rhamnose Moiety of Solamargine Plays a Crucial Role in Triggering Cell Death by Apoptosis. Biochemical and Biophysical Research Communications, 242, 21-25. https://doi.org/10.1006/bbrc.1997.7903

[18] Badami, S., Manohara Reddy, S.A., Kumar, E.P., Vijayan, P. and Suresh, B. (2003) Antitumor Activity of Total Alkaloid Fraction of Solanum pseudocapsicum Leaves. Phytotherapy Research, 17, 1001-1004.

[19] Esteves-Souza, A., Sarmento da Silva, T., A loes, C.C.F., Carvalho, M., Braz-Filho, R. and Echevarria, A. (2002) Cytotoxic Activities against Ehrlich Carcinoma, Human K562 Leukaemia of Alkaloids and Flavonoids from Two Solanum Species. Journal of the Brazilian Chemical Society, 13, 838-842. https://doi.org/10.1590/S0103-50532002000600017

[20] Chataing, B., Christancho, N.B. and Usubillaga, A. (1998) Topical Treatment of Herpes Simplex, Herpes Zoster and Genital Herpes with a Mixture of Solanaceous Glycoalkaloids. MedULA, 7, 30-34.

[21] Chami, L.A., Méndez, R.B., Chataing, J., O’Callaghan, A., Usubillaga, A. and LaCruz, L. (2003) Toxicological Effects of $\alpha$-Solamargine in Experimental Animals. 
Phytotherapy Research, 17, 254-258.

[22] Hall, C.A., Hobby, T. and Cipollini, M. (2006) Efficacy and Mechanisms of $\alpha$-Solasonine- and $\alpha$-Solamargine-Induced Cytolysis on Two Strains of Trypanosoma cruzi. Journal of Chemical Ecology, 32, 2405-2416. https://doi.org/10.1007/s10886-006-9153-5

[23] Verpoorte, R. (1998) Exploration of Nature's Chemodiversity: The Role of Secondary Metabolites as Leads in Drug Development. Drug Discovery Today, 3, 232-238. https://doi.org/10.1016/S1359-6446(97)01167-7

[24] Roddick, J.G., Rÿrenber, A.L. and Weissenber, M. (1990) Membrane-Disrupting Properties of the Steroidal Glycoalkaloids Solasonine and Solamargine. Phytochemistry, 29, 1513-1518. https://doi.org/10.1016/0031-9422(90)80111-S

[25] Munari, C.C., de Oliveira, P.F., Campos, J.C.L., Martins, S.P.L., Da Costa, J.C., Bastos, J.K. and Tavares, D.C. (2014) Antiproliferative Activity of Solanum lycocarpum Alkaloidal Extract and Their Constituents, Solamargine and Solasonine, in Tumor Cell Lines. Journal of Natural Medicines, 68, 236-241. https://doi.org/10.1007/s11418-013-0757-0

[26] Xu, X.H., Zhang, L., Wu, G.S., Chen, X., Li, T., Chen, X., Wang, Y.T. and Lu, J.J. (2017) Solasodine Induces Apoptosis, Affects Autophagy, and Attenuates Metastasis in Ovarian Cancer Cells. Planta Medica, 83, 254-260.

[27] Yu, S., Sheu, H.M. and Lee, C.H. (2017) Solanum incanum Extract (SR-T100) Induces Melanoma Cell Apoptosis and Inhibits Established Lung Metastasis. Oncotarget, 8, 103509-103517.

[28] Lipscombe, R.J., Carter, S.J. and Ruane, M. (2005) Rhamnose Binding Protein. US Patent No. 6930171.

[29] Cham, B.E. and Daunter, B. (1990) Solasodine Glycosides. Selective Cytotoxicity for Cancer Cells and Inhibition of Cytotoxicity by Rhamnose in Mice with Sarcoma 180. Cancer Letters, 55, 221-225. https://doi.org/10.1016/0304-3835(90)90122-E

[30] Wang, Y., Gao, J., Gu, G., Li, G., Cui, C., Sun., B. and Hongxiang, L. (2011) In Situ RBL Receptor Visualization and Its Mediated Anticancer Activity for Solasodine Rhamnosides. ChemBioChem, 12, 2418-2420.

[31] Cham, B.E. (2000) Medicinal Compositions and Their Method of Preparation. Patent No. WO 00/61153.

[32] Cham, A., Cham, K., Chase T. and Cham, B.E. (2015) A Standardized Plant Extract Containing a Target Compound Is Acceptable as a Potent Therapeutic Entity: Relevance to BEC and Solamargine, A Topical Clinical Formulation Curaderm ${ }^{\mathrm{BEC} 5}$. Journal of Cancer Treatment and Research, 3, 22-27. https://doi.org/10.11648/j.jctr.20150302.12

[33] Shen, K.H., Hung, J.H., Chang, C.W., Weng, Y.T., Wu, M.J. and Chen, P.S. (2017) Solasodine Inhibits Invasion of Human Lung Cancer Cell through Downregulation of miR-21 and MMP Expression. Chemico-Biological Interactions, 268, 129-135. https://doi.org/10.1016/j.cbi.2017.03.005

[34] Zhuang, Y., Wu, C., Zhou, J., Chen, X., Wu, J., Jiang, S., Peng, H., Zou, X., Liu, J., Gong, T., Qi, M., Xue, T., Liu, S. and Cai, H. (2017) Solasodine Inhibits Human Colorectal Cancer Cells through Suppression of AKT/Glycogen Synthase Kinase-3 $\beta$ l $\beta$-Catenin Pathway. Cancer Science, 108, 2248-2264.

[35] Koduru, S., Grierson, D.S., Venter, M. and Afolayan, A.J. (2007) Anticancer Activity of Steroidalkaloids Isolated from Solanum aculeastrum. Pharmaceutical Biology, 45, 613-618. https://doi.org/10.1080/13880200701538690 
[36] Jayakumar, K. and Murugan, K. (2017) Purified Solasodine and Caulophyllumine: A from Solanum mauritianum Scop. against MCF-7 Breast Cancer Cell Lines in Terms of Cell Growth, Cell Cycle and Apoptosis. Journal of Pharmacognosy and Phytochemistry, 6, 472-478.

[37] Hameed, A., Ijaz, S., Mohammad, I.S., Muhammad, K.S., Akhtar, N. and Khan, H.M.S. (2017) Aglycone Solanidine and Solasodine Derivatives: A Natural Approach towards Cancer. Biomedicine \& Pharmacotherapy, 94, 446-457. https://doi.org/10.1016/j.biopha.2017.07.147

[38] Xie, X., Zhu, H., Yang, H., Huang, W., Wu, Y., Wang, Y., Luo, Y., Wang, D. and Shao, G. (2015) Solamargine Triggers Hepatoma Cell Death through Apoptosis. Oncology Letters, 10, 168-174. https://doi.org/10.3892/ol.2015.3194

[39] Shiu, L.Y., Liang, C.H., Chang, L.C., Sheu, H.M., Tsai, E.M. and Kuo, K.W. (2009) Solamargine Induces Apoptosis and Enhances Susceptibility to Trastuzumab and Epirubicin in Breast Cancer Cells with Low or High Expression Levels of HER2/neu. Bioscience Reports, 29, 35-45. https://doi.org/10.1042/BSR20080028

[40] Li, X., Zhao, Y., Wu, W.K., Liu, S., Cui, M. and Lou, H. (2011) Solamargine Induces Apoptosis with p53 Transcription-Dependent and Transcription-Independent Pathways in Human Osteosarcoma U2OS Cells. Life Sciences, 88, 314-321. https://doi.org/10.1016/j.lfs.2010.12.006

[41] Shiu, L.Y., Chang, L.C., Liang, C.H., Huang, Y.S., Sheu, H.M. and Kuo, K.W. (2007) Solamargine Induces Apoptosis and Sensitizes Breast Cancer Cells to Cisplatin. Food and Chemical Toxicology, 45, 2155-2164. https://doi.org/10.1016/j.fct.2007.05.009

[42] Zhou, Y., Tang, Q., Zhao, S., Zhang, F., Li, l., Wu, W., Wang, Z. and Hann, S. (2014) Targeting Signal Transducer and Activator of Transcription 3 Contributes to the Solamargine-Inhibited Growth and -Induced Apoptosis of Human Lung Cancer Cells. Tumor Biology, 35, 8169-8178. https://doi.org/10.1007/s13277-014-2047-1

[43] Punjabi, S., Cook, I., Kersey, P., Marks, R., Finlay, A., Sharpe, G. and Cerio, R. (2000) A Double Blind, Multi-Centre Parallel Group Study of BEC-5 Cream in Basal Cell Carcinoma. JEu Acad Dermatol Venerol,14, 47-60.

[44] Tambuscio, A., Siliprandi, L., Dario, M., Cham, A., Cham, B. and Bordignon, M. (2016) Treatment of Cutaneous Carcinomas with a Topical Cream Containing Solasodine Rhamnosides: Focus on Efficacy, Compliance and Cosmetic Outcomes. European Academy of Dermatology and Venereology Congress, Athens, May 2016 19-22.

[45] Cham, B.E., Daunter, B. and Evans, R. (1991) Topical Treatment of Malignant and Premalignant Skin Lesions by Very Low Concentrations of a Standard Mixture (BEC) of Solasodine Glycosides. Cancer Letters, 59, 183-192. https://doi.org/10.1016/0304-3835(91)90140-D

[46] Cham, B.E. (2007) The Eggplant Cancer Cure: A Treatment for Skin Cancers and New Hope for Other Cancers from Nature's Pharmacy. Smart Publications, Petalum.

[47] Cham, B.E. (2007) Solasodine Rhamnosyl GlycosidesSpecifically Bind Cancer Cell Receptors and Induce Apoptosis and Necrosis. Treatment for Skin Cancer and Hope for Internal Cancers. Research Journal of Biological Sciences, 2, 503-514.

[48] Cham, B.E. (2007) Solasodine Rhamnosyl Glycosides in a Cream Formulation Is Effective for Treating Large and Troublesome Skin Cancers. Research Journal of Biological Sciences, 2, 749-761.

[49] Cham, B.E. (2008) Cancer Intralesion Chemotherapy with Solasodine Rhamnosyl 
Glycosides. Research Journal of Biological Sciences, 3, 1008-1017.

[50] Cham, B.E. (2009) When Does Alternative Become Orthodox? Skin Cancer Treatment with Solasodine Rhamnosyl Glycosides in Its Transitional Stage, a Case Study. Evidence-Based Complementary and Alternative Medicine, 6, 415-420.

[51] Cham, B.E. (2011) Topical Solasodine Rhamnosyl Glycosides Derived from the Eggplant Treats Large Skin Cancers: Two Case Reports. International Journal of Clinical Medicine, 2, 473-477. https://doi.org/10.4236/ijcm.2011.24080

[52] Chase T.R. (2011) Curaderm ${ }^{\mathrm{BEC} 5}$ for Skin Cancers, Is It? An Overview. Journal of Cancer Therapy, 2, 728-745. https://doi.org/10.4236/jct.2011.25099

[53] Cham, B.E. (2012) Intralesion and Curaderm BEC Topical Combination Therapies of Solasodine Rhamnosyl Glycosides Derived from the Eggplant or Devil's Apple Result in Rapid Removal of Large Skin Cancers. Methods of Treatment Compared. International Journal of Clinical Medicine, 3, 115-124. https://doi.org/10.4236/ijcm.2012.32024

[54] Cham, B.E. (2013) Topical Curaderm ${ }^{\mathrm{BEC} 5}$ Therapy for Periocular Nonmelanoma Skin Cancer: A Review of Clinical Outcomes. International Journal of Clinical Medicine, 4, 233-238. https://doi.org/10.4236/ijcm.2013.45041

[55] Cham, B.E. (2013) Solasodine Glycosides: A Topical Therapy for Actinic Keratosis. A Single-Blind, Randomized, Placebo-Controlled, Parallel Group Study with Curaderm $^{\mathrm{BEC}}$. Journal of Cancer Therapy, 4, 588-596. https://doi.org/10.4236/jct.2013.42076

[56] Cham, B.E. (2014) A Review of Solasodine Rhamnosides Therapy for In-Situ Squamous Cell Carcinoma on the Penis. British Journal of Medicine and Medical Research, 4, 621-631.

[57] Cham, A. and Cham, B.E. (2015) Treatment of Skin Cancer with a Selective Apoptotic-Inducing Curaderm ${ }^{\mathrm{BEC} 5}$ Topical Cream Containing Solasodine Rhamnosides. International Journal of Clinical Medicine, 6, 326-333. https://doi.org/10.4236/ijcm.2015.65042

[58] Cham, B.E., Cham, K., Cham, A., Chase, T. and Zhou, V. (2015) Treatment of Non Melanoma Skin Cancers: An Intra-Comparison Study of Curaderm ${ }^{\mathrm{BEC} 5}$ and Various Established Modalities. Journal of Cancer Therapy, 6, 1045-1053. https://doi.org/10.4236/jct.2015.612114

[59] Batsev, A.F., Dobrokhotova, V.Z. and Cham, B.E. (2016) Topical Cream Curaderm${ }^{\mathrm{BEC} 5}$ Treats a Recalcitrant Basal Cell Carcinoma. Clinical Medical Reviews and Case Reports, 3, Article No. 098.

[60] Goldberg, L.H., Landau, J.M., Moody, M.N. and Vergilis-Kalner, I.J. (2011) Treatment of Bowen's Disease on the Penis with Low Concentrations of a Standard Mixture of Solasodine Glycosides and Liquid Nitrogen. Dermatologic Surgery, 37, 858-861. https://doi.org/10.1111/j.1524-4725.2011.02014.x

[61] Punjabi, S., Cook, L.J., Kersey, P., Marks, R. and Cerio, R. (2008) Solasodine Glycoalkaloids: A Novel Topical Therapy for Basal Cell Carcinoma. A Double Blind, Randomized, Placebo-Controlled, Parallel Group, Multicentre Study. International Journal of Dermatology, 47, 78-82.

[62] Bordingnon, M. (2016) Efficacy and Safety of Curaderm ${ }^{\mathrm{BEC} 5}$ in the Treatment of Basal Cell Carcinoma: A Pilot Study in the Italian Population. European Academy of Dermatology and Venereology Congress, Athens.

[63] Dobrokhotova, F.Z., Betsev, A.F. and Belysheva, T.S. (2016) The Use of Kuraderm Drug in the Treatment of Basal Cell Carcinoma of the Head and Neck. Head and Neck Tumors, 6, 22-26. https://doi.org/10.17650/2222-1468-2016-6-3-22-26 
[64] Li, X., Zhao, Y., Liu, S., Cui, M. and Lou, H. (2011) Induction of Actin Disruption and Downregulation of P-Glycoprotein Expression of Solamargine in Multidrug-Resistant K562/A02 Cells. Chinese Medical Journal, 124, 2038-2044.

[65] Friedman, M. (2015) Chemistry and Anticarcinogenic Mechanisms of Glycoalkaloids Produced by Eggplants, Potatoes and Tomatoes. Journal of Agricultural and Food Chemistry, 63, 3323-3337. https://doi.org/10.1021/acs.jafc.5b00818

[66] Jiang, Q., Chen, M., Cheng, K., Yu, P., Wei, X. and Shi, Z. (2016) Therapeutic Potential of Steroidal Alkaloids in Cancer and Other Diseases. Medicinal Research Reviews, 36, 119-143.

[67] Kessenbrock, K., Plaks, V. and Werb, Z. (2010) Matrix Metalloproteinases: Regulators of the Tumor Microenvironment. Cell, 141, 52-67. https://doi.org/10.1016/j.cell.2010.03.015

[68] Sani, I.K., Marashi, S.H. and Kalalinia, F. (2015) Solamargine Inhibits Migration and Invasion of Human Hepatocellular Carcinoma Cells through Down-Regulation of Matrix Metalloproteinases 2 and 9 Expression and Activity. Toxicology in Vitro, 29, 893-900. https://doi.org/10.1016/j.tiv.2015.03.012

[69] Cham, B.E. and Chase, T.R. (2012) Solasodine Rhamnosyl Glycosides Cause Apoptosis in Cancer Cells. Do They Also Prime the Immune System Resulting in Long Term Protection against Cancer? Planta Medica, 78, 349-353. https://doi.org/10.1055/s-0031-1298149

[70] Van der Most, R.G., Himbeck, R., Aarons, S., Carter, S.J., Larma, I., Robinson, C., Currie, A. and Lake, R.A. (2006) Antitumor Efficacy of the Novel Chemotherapeutic Agent Coramsine Is Potentiated by Cotreatment with CpG-Containing Oligodeoxynucleotides. Journal of Immunotherapy, 29, 134-142. https://doi.org/10.1097/01.cji.0000187958.38179.a9

[71] Chataing, B., Concepcion, J.L., Buitrago de Cristancho, N. and Usubillaga, A. (2001) Clinical Study of the Effectiveness of Extracts Alkaloids Obtained of the Fruits of Solanum americanum Miller on Herpes Simplex, Herpes Two Zoster and Genital Herpes. MedULA, 7, 30-35.

[72] Thorne, H.V., Clarke, G.F. and Skuce, R. (1985) The Inactivation of Herpes Simplex Virus by Some Solanaceae Glycoalkaloids. Antiviral Research, 5, 335-343. https://doi.org/10.1016/0166-3542(85)90003-8

[73] Basu, A. and Lahiri, S.C. (1977) Some Pharmacological Actions of Solasonine. Indian Journal of Experimental Biology, 15, 85-289.

[74] SolbecPharmaceut (2005) Pre-IND Submission 5.

[75] Friedman, M., Henika, P.R. and Mackay, B.E. (1996) Feeding of Potato, Tomato and Eggplant Alkaloids Affects Food Consumption and Body and Liver Weights in Mice. Journal of Nutrition, 126, 989-999.

[76] Xiang, S.T., Zhang, Q.H., Tang, Q., Zheng, F., Wu, J.J., Yang, L.J. and Hann, S.S. (2016) Activation of AMPK $\alpha$ Mediates Additive Effects of Solamargine and Metformin on Suppressing MUC 1 Expression in Castration-Resistant Prostate Cancer Cells. Scientific Reports, 6, Article No. 36721. https://doi.org/10.1038/srep36721

[77] Keeler, R.F., Baker, D.C. and Gaffield, W. (1990) Spirosolane-Containing Solanum Species and Induction of Congenital Craniofacial Malformations. Toxicon, 28, 873-884. https://doi.org/10.1016/0041-0101(90)90017-2

[78] Zeng, X., Xu, L., Liang, Y., Xiao, W., Xie, L., Zhang, Y., Zhao, L., Cao, L., Chen, J. and Wang, G. (2011) Quantitative Determination and Pharmacokinetic Study of 
Solamargine in Rat Plasma by Liquid Chromatography-Mass Spectrometry. Journal of Pharmaceutical and Biomedical Analysis, 55, 1157-1162.

https://doi.org/10.1016/j.jpba.2011.04.007

[79] Millward, M., Powell, A., Daly, P., Tyson, S., Ferguson, R. and Carter, S. (2006) Results of Phase 1 Clinical Trials of Coramsine in Patients with Advanced Solid Tumors. Journal of Clinical Oncology, 24, 2070.

\section{Abbreviations}

AUC: area under the curve

BEC: mixture of solasodine glycosides

Cmax: maximum plasma concentration

DLT: dose-limiting toxicities

EEL: endogenous endocytic lectin

EMT: epithelial-mesenchymal transition

$\mathrm{ED}_{50}$ : effective dose, for $50 \%$ of a test population receiving the drug

$\mathrm{IC}_{50}$ : half maximal inhibitory concentration

$\mathrm{LD}_{50}$ : amount of agent to kill $50 \%$ of a test population

MDR: multi-drug resistance

MMP: matrix metalloproteinase

MTD: maximum tolerated dose

RBP: rhamnose binding protein

SG: solasodine glycoside

SM: solamargine

SS: solasonine

T1/2: plasma half-life

TI: therapeutic index 